\title{
Is Accurate Perception of Body Image Associated with Appropriate Weight-Control Behavior among Adolescents of the Seychelles
}

\author{
Heba Alwan, ${ }^{1}$ Bharathi Viswanathan, ${ }^{2}$ Fred Paccaud, ${ }^{1}$ and Pascal Bovet ${ }^{1,2}$ \\ ${ }^{1}$ Institute of Social and Preventive Medicine (IUMSP), University Hospital Centre and University of Lausanne, Rue du Bugnon 17, \\ 1005 Lausanne, Switzerland \\ ${ }^{2}$ Unit for Prevention and Control of Cardiovascular Disease, Department of Public Health, Ministry of Health, Victoria, Seychelles
}

Correspondence should be addressed to Pascal Bovet, pascal.bovet@chuv.ch

Received 29 September 2010; Accepted 26 January 2011

Academic Editor: Andrew P. Hills

Copyright (C) 2011 Heba Alwan et al. This is an open access article distributed under the Creative Commons Attribution License, which permits unrestricted use, distribution, and reproduction in any medium, provided the original work is properly cited.

\begin{abstract}
Background. We examined body image perception and its association with reported weight-control behavior among adolescents in the Seychelles. Methods. We conducted a school-based survey of 1432 students aging 11-17 years in the Seychelles. Perception of body image was assessed using both a closed-ended question (CEQ) and Stunkard's pictorial silhouettes (SPS). Voluntary attempts to change weight were also assessed. Results. A substantial proportion of the overweight students did not consider themselves as overweight (SPS: 24\%, CEQ: 34\%), and a substantial proportion of the normal-weight students considered themselves as too thin (SPS: 29\%, CEQ: 15\%). Logistic regression analysis showed that students with an accurate weight perception were more likely to have appropriate weight-control behavior. Conclusions. We found that substantial proportions of students had an inaccurate perception of their weight and that weight perception was associated with weight-control behavior. These findings point to forces that can drive the upwards overweight trends.
\end{abstract}

\section{Background}

The prevalence of overweight and obesity (jointly referred to as "overweight" in this paper) among adolescents is increasing worldwide [1]. Overweight during adolescence tends to track into adulthood [2] and is associated with a variety of chronic diseases $[3,4]$ and psychosocial sequelae [5]. However, interventions to prevent or reduce overweight, both at the individual and population levels, have so far had little success [6].

Accurate perception of one's own weight status may enable or facilitate appropriate weight-control behaviors [7, 8]. Conversely, underestimating one's own weight is associated with increased risk of developing overweight $[1,9]$. In a cross-sectional study, overweight/obese African American adolescents who perceived themselves as underweight were more likely to attempt to gain weight $(\mathrm{OR}=12.4,95 \% \mathrm{CI}$ : 5.6-27.4) [8]. Similarly, in a cohort study with a 13-year followup, obese women who perceived themselves as normal weight gained $0.31 \mathrm{~kg} / \mathrm{m}^{2}$ annually, while those who accurately perceived themselves as obese lost $0.09 \mathrm{~kg} / \mathrm{m}^{2}$ annually $(P<.001)$ [7]. Several models may help to frame the development and/or prevention of overweight in relation to an individual's perception of being overweight, for example, the health belief model [10] and the transtheoretical model [11].

Perception of weight and body image is also influenced by social norms and culture [12,13]. For example, studies have indicated that black females had larger body size ideals in both the USA $[14,15]$ and Sub-Saharan Africa [13, 16, 17] than their white counterparts and that they tend to be more satisfied with their actual body size than white females $[14,15]$. Correspondingly, "plumpness" is perceived as a sign of beauty, attractiveness, and wealth in some cultures $[13,18]$. While an ideal for heavier body image may protect black females from developing anorexia-type eating disorders [19], it may increase their risk for overweight $[20,21]$. However, attitudes towards body weight may be changing over time, and a preference for a thin body image 
is presently observed among adolescents in some developing countries, for example, Bahrain and Saudi Arabia $[9,22]$.

We examined body image perception and weight-related behaviors among adolescents of the Seychelles. Seychelles comprises a group of islands located approximately $1800 \mathrm{~km}$ east of Kenya with the majority of the population being of African descent. With a gross domestic product per capita of approximately $\$ 8000$ in 2007, the Seychelles is considered an upper middle-income country. Almost 100\% of children attend school up to the 10th grade with approximately $96 \%$ in public schools. The prevalence of overweight and obesity among boys and girls has increased from 10.2\% in 1998 to $16.1 \%$ in $2004[23,24]$.

We hypothesized that appropriate weight-control behavior is associated with accurate perception of one's own body image. To our knowledge, our study is the first to assess the relationship between accurate body image perception and appropriate weight-related behavior among adolescents in the Sub-Saharan African region. Moreover, most studies conducted in Sub-Saharan Africa have solely investigated body image perception among females and not among males.

\section{Materials and Methods}

The data in this study is derived from the Global Schoolbased Student Health Survey (GSHS) [25] conducted in 2007. General methods and overall results of this survey have been previously published $[25,26]$. Briefly, a two-stage cluster sample was employed to produce a representative sample of all secondary school students in the country. A selfadministered and anonymous questionnaire was conducted among 1432 students aging 11-17 years, which corresponded to a response rate of $82 \%$. The questionnaire addressed various topics such as demographics, dietary behaviors, physical activity, and sedentary behaviors, as well as tobacco and alcohol use.

Various instruments exist for assessing body image perception, including pictorial constructs $[9,15,27-31]$, as well as structured questions ("narrative" description of weight) $[8,9,32]$. In our study, we employed both a narrative construct and a pictorial construct for classifying body image in three categories (corresponding to underweight, normal weight, and overweight). Regarding the pictorial constructs, respondents were given Stunkard's pictorials silhouettes (SPS) [33] from which they had to choose the silhouette that most closely resembled how they look (current body image) and how they would like to look (ideal body image). A body image discrepancy (BID) variable was created by subtracting the ideal body image chosen by the respondent from the current perceived body image. As in previous reports [15], BID measures body size satisfaction whereby a high BID score implies low satisfaction with one's body size, and a low BID score implies a higher level of satisfaction with body size. Because the number of possible answers in our questionnaire could not exceed eight (due to contingencies related to automatic optical character recognition used for extracting data from the answer sheets in the GSHS), the leanest pictorial silhouette was omitted from the original questionnaire that includes nine silhouettes. The choice for this omission was based on the fact that overweight is a highly prevailing problem in Seychelles [23] while undernutrition of clinical significance is virtually nonexistent in Seychelles at present. The hair in the silhouettes was colored black to conform with the African descent of the majority of students of Seychelles. In this study, silhouettes 1-3 were chosen to represent the "thin" category, silhouette 4 to represent the "normal body weight category," and silhouettes 5-8 to represent the "overweight" category.

Respondents were further asked about their own perceived weight using a closed-ended question (CEQ) reading: "How do you describe your weight: very underweight, slightly underweight, about the right weight, slightly overweight, or very overweight." An additional question inquired about what the students were doing regarding their current weight status using the following closed-ended question: "Which of the following are you trying to do about your weight: I am not trying to do anything about my weight, lose weight, gain weight, stay the same weight."

Weight and height were measured using standard equipment, and administrators registered the values one day before the questionnaire was administered. The following day, these values were given to the students to be copied on to their answer sheets before completing the anonymous GSHS questionnaire (this ensured that the students' responses to the GSHS questionnaire remained anonymous). Body weight categories in children, which are based upon BMI cut-offs that vary according to age and sex up to the age of 18 , were defined along international criteria $[34,35]$. These cut-offs in children are expected to correspond to BMI values in adults (starting at the age of 18 years) of 18.5 (thinness), 25 (overweight), and 30 (obesity).

Analyses in this paper were restricted to the students ( $n=873)$ who had full data for all variables relevant to this paper. Answers were missing in 408 students for height and weight (measured on the day before the survey), in 85 for current body image (Stunkard), 73 for ideal body image, 55 for the CEQ, 39 for weight-related behavior, 5 for age, and 15 for gender. There were virtually no differences in the distribution of characteristics (age, sex, grade, and ideal body image) between students with versus without missing data. Weight perception was not assessed for thin students (i.e., a corresponding $\mathrm{BMI}<18.5$ ).

All results were stratified by gender and actual weight status. With regard to the two instruments used to assess weight perception, we tested whether classification based on either instrument concurs using the chi-square test and the kappa statistic. We tested differences in reported weightrelated behavior according to categories of weight perception using the Pearson's chi-squared test. The mean and standard deviation of the adolescents' perceived ideal body image was calculated, and differences between gender and weight status categories were tested using the Student's $t$-test and Cusik's trend test, respectively. The association between participants' weight perception and reported weight-related behavior categories was tested with the chi-square test. The association between weight perception and weight-related 
TABLE 1: Selected characteristics of the participants.

\begin{tabular}{lcccccc}
\hline & \multicolumn{2}{c}{ All $(n=873)$} & \multicolumn{2}{c}{ Boys $(n=397)$} & \multicolumn{2}{c}{ Girls $(n=476)$} \\
& Mean (SD) or $N$ & $\%$ & Mean (SD) or $N$ & $\%$ & Mean (SD) or $N$ & $\%$ \\
\hline $\begin{array}{l}\text { Mean age (yr) } \\
\text { BMI category* }\end{array}$ & $14.1(1.5)$ & $14.1(1.5)$ & & & $14.1(1.4)$ \\
$\quad$ Thin & & & & & & \\
Normal & 123 & 14.1 & 47 & 11.8 & 76 & 16.0 \\
weight & 558 & 63.9 & 274 & 69.0 & 284 & 59.7 \\
Overweight & 130 & 14.9 & 53 & 13.4 & 77 & 16.2 \\
Obese & 62 & 7.1 & 23 & 5.8 & 39 & 8.2 \\
\hline
\end{tabular}

* BMI categories, which vary according to age and sex in children, are defined according to international references $[34,35]$.

TABle 2: Agreement between answers to the two questions on selfperceived weight.

\begin{tabular}{llcccc}
\hline & & \multicolumn{5}{c}{ Stunkard's pictorial silhouettes } \\
& $1-3$ & 4 & $5-8$ & Total \\
\hline \multirow{3}{*}{$\begin{array}{l}\text { Narrative } \\
\text { description } \\
\text { of weight }\end{array}$} & $\begin{array}{l}\text { Normal } \\
\text { weight }\end{array}$ & 30.4 & 49.1 & 20.5 & 100.0 \\
& Overweight & 8.6 & 17.7 & 73.7 & 100.0 \\
\hline
\end{tabular}

behavior was also assessed using logistic regression adjusted for age and sex. All analyses were performed using Stata 9.2.

\section{Results}

Among all the participants, $14.1 \%$ were thin, $63.9 \%$ were normal weight, $14.9 \%$ were overweight, and $7.1 \%$ were obese (Table 1). The prevalence of overweight and obesity was higher among girls than boys. The "overweight" and "obese" categories were combined in all other analyses.

The distribution of the answers to the two questions on self-perceived weight (CEQ and SPS) is displayed in Table 2. The categorical answers to the questions correlated well with a chi-square $<0.001$ and a kappa of $55.6 \%$. Therefore, the majority of students who perceived themselves as being "underweight" using the CEQ chose silhouettes 1-3 as their perceived current body image, and so forth.

Figure 1 displays the distribution of categories of one's perceived body image according to sex and actual weight status categories. While the majority of the boys with a normal weight selected silhouette 4 (representing the "normal-weight" category) as their current body size (61\%), $76 \%$ of the girls with a normal weight chose from silhouettes 1-4 (39\% chose silhouette 4 and 37\% chose silhouette 1-3). Among the overweight students, $76 \%$ of both the boys and the girls chose from silhouettes 5-8 (representing the "overweight" category) as their perceived current body image.

Regarding the closed-ended question (CEQ), large proportions of the normal-weight and overweight students accurately perceived themselves as "about the right weight"

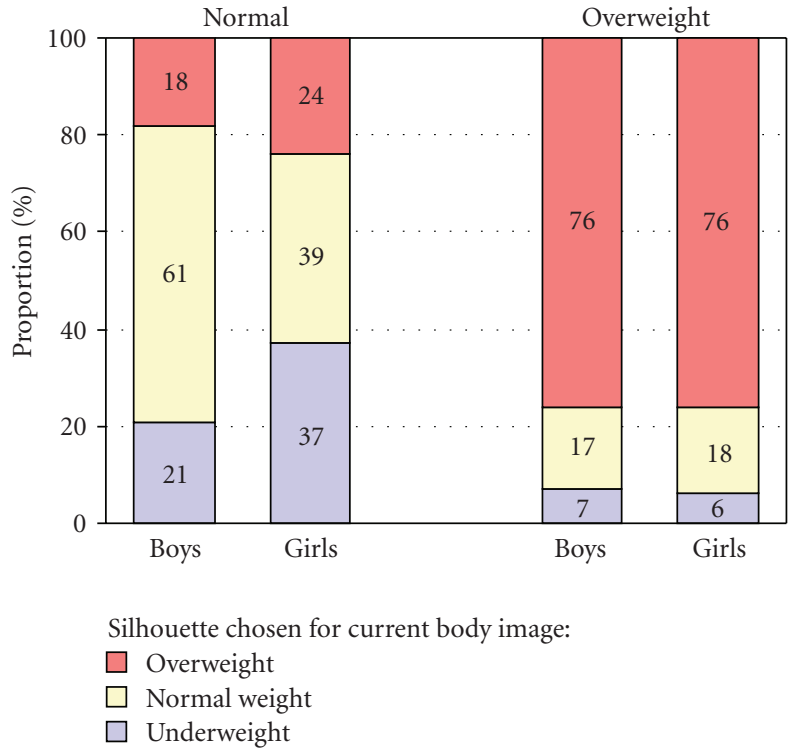

FIGURE 1: Self-perceived body image based on Stunkard's silhouettes according to sex and actual weight status.

and "overweight," respectively (Figure 2). Among the normal-weight adolescents, a substantial proportion of the students (15\%) inaccurately considered themselves to be "underweight." Among the overweight students, a substantial proportion of them did not perceive to be overweight (i.e., they inaccurately considered themselves as either "right weight" or "underweight"), and this proportion was almost twice as great among the boys than the girls ( $46 \%$ versus $26 \%, P=.004)$.

Regarding the ideal body image reported by students, there was some concordance in the perception of one's own ideal body image among normal-weight, overweight, and obese students, suggesting that students' actual weight status did not greatly influence students' body image ideals, although more obese students than lean students reported a larger body image (Figure 3$)$. The mean $( \pm$ SD) ideal body silhouette increased from $3.83 \pm 0.86$ to $3.91 \pm 0.84$ and $4.37 \pm 0.81$ across categories of normal-weight, overweight, and obese students (trend test: $P<.001$ ). Girls tended to 


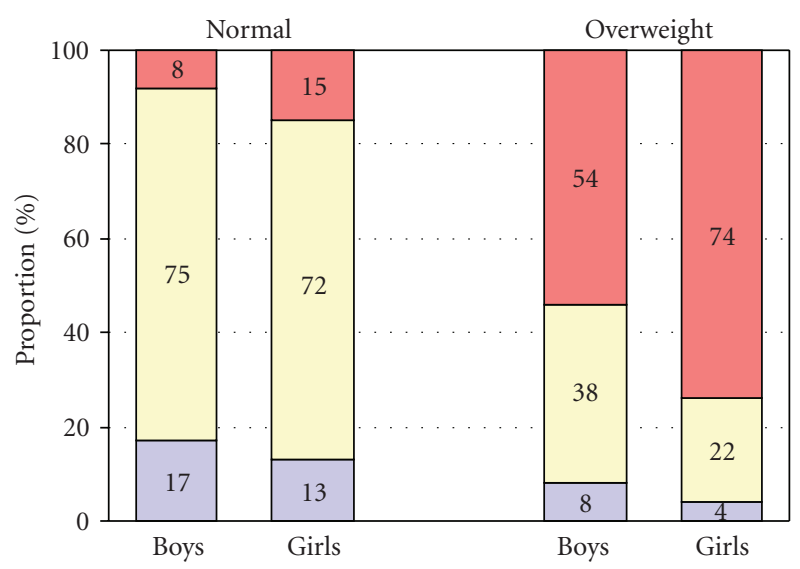

How do you describe your weight?
$\square$ Overweight
$\square$ Right weight
$\square$ Underweight

FIGURE 2: Narrative description of self-perceived weight according to sex and actual weight status.

TABLE 3: Association between body image discrepancy (BID) and weight-control behavior.

\begin{tabular}{lcccc}
\hline & $\begin{array}{c}\text { Normal weight } \\
\text { Trying to } \\
\text { gain weight } \\
(\%)\end{array}$ & $N$ & $\begin{array}{c}\text { Overweight } \\
\text { Trying to } \\
\text { lose weight } \\
(\%)\end{array}$ \\
\hline BID $^{*}$ & 22 & 45 & 2 & 100 \\
-2 or less & 105 & 51 & 8 & 38 \\
-1 & 280 & 15 & 35 & 40 \\
0 & 129 & 5 & 82 & 85 \\
1 & 22 & 18 & 65 & 88 \\
2 or more & 22 & & & \\
\hline
\end{tabular}

${ }^{*}$ BID: score for current body image minus score for ideal body image.

have leaner body image ideals than boys (mean \pm SD ideal silhouette: $3.78 \pm 0.88$ versus $4.01 \pm 0.83$, resp.; $P<.001$ ).

The association between body image discrepancy (BID) and weight-control behavior is displayed in Table 3. Among normal-weight adolescents, students who had a body image discrepancy (BID) of less than 0 (i.e., their current body image was smaller than their ideal body image) were more likely to report trying to gain weight. Among overweight adolescents, individuals who had a BID of 0 or more (i.e., their current body image was equal to or larger than their ideal body image) were generally more likely to report attempting to lose weight.

Figure 4 displays what boys and girls were attempting to do about their weight according to actual weight status categories. Among the normal-weight students, one in five students inappropriately wanted to gain weight, with no difference between boys and girls (23\% versus 19\%, ns). Approximately half of the normal-weight students reported

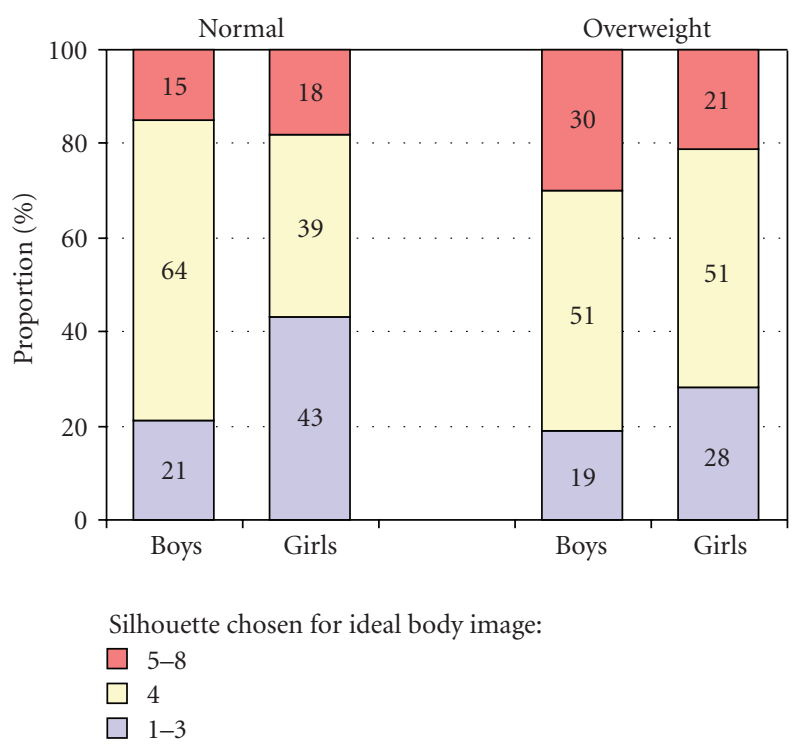

Figure 3: Ideal own body image based on Stunkard's silhouettes according to sex and actual weight status.

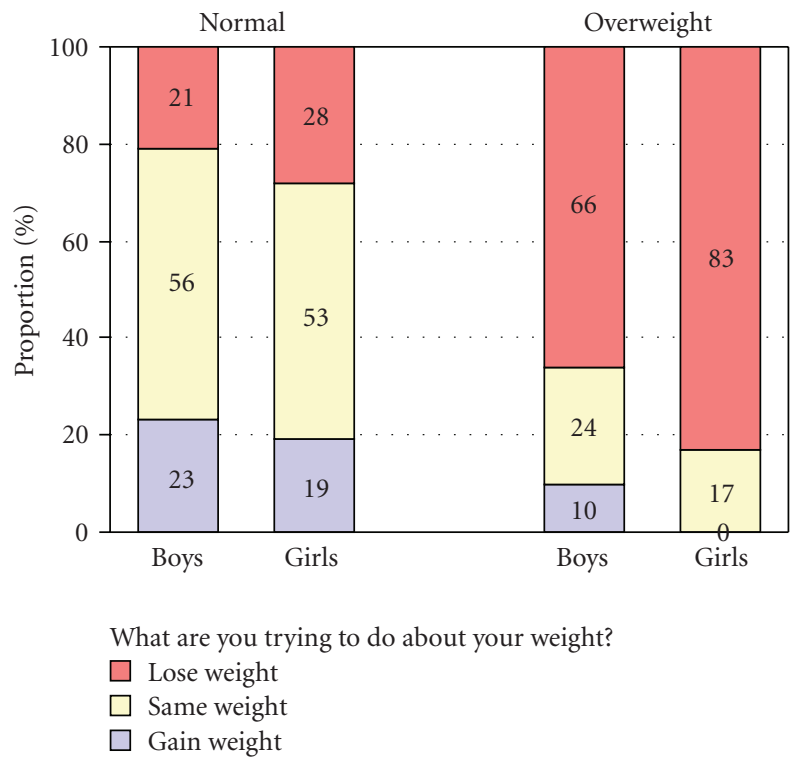

FIGURE 4: Weight-related behavior according to sex and actual weight status.

they were doing nothing to change their weight, and around one quarter were trying to lose weight. Among the overweight students, girls were more likely to report trying to lose weight than boys ( $83 \%$ versus $66 \%$ resp.; $P=.007$ ), while $24 \%$ of the overweight boys and $17 \%$ of the overweight girls were not doing anything to change their weight. None of the overweight girls reported trying to gain weight, as compared to $10 \%$ of overweight boys $(P<.001)$.

Reported weight-control behavior according to one's own perceived body image (using either CEQ or SPS) and actual weight status is presented in Table 4. Normal-weight 
TABLE 4: Association between self-perceived weight and weight-control behavior among normal-weight and overweight boys and girls.

\begin{tabular}{|c|c|c|c|c|c|c|c|c|c|}
\hline & & \multicolumn{4}{|c|}{ Normal weight } & \multicolumn{4}{|c|}{ Overweight } \\
\hline & & $\begin{array}{l}\text { Perceived } \\
\text { him/herself as }\end{array}$ & $N$ & $\begin{array}{c}\text { Trying to gain } \\
\text { weight }(\%)\end{array}$ & $P$ & $\begin{array}{l}\text { Perceived } \\
\text { him/herself as }\end{array}$ & $N$ & $\begin{array}{c}\text { Trying to lose } \\
\text { weight }(\%)\end{array}$ & $P$ \\
\hline \multirow{4}{*}{$\begin{array}{l}\text { Stunkard's } \\
\text { pictorial } \\
\text { silhouettes }\end{array}$} & \multirow{2}{*}{ Boys } & Underweight & 57 & 47 & \multirow{2}{*}{.000} & Overweight & 58 & 72 & \multirow{2}{*}{.029} \\
\hline & & Not underweight & 217 & 17 & & Not overweight & 18 & 44 & \\
\hline & \multirow{2}{*}{ Girls } & Underweight & 104 & 27 & \multirow{2}{*}{.007} & Overweight & 88 & 86 & \multirow{2}{*}{.068} \\
\hline & & Not underweight & 180 & 14 & & Not overweight & 28 & 71 & \\
\hline \multirow{4}{*}{$\begin{array}{l}\text { Narrative } \\
\text { description of } \\
\text { weight }\end{array}$} & \multirow{2}{*}{ Boys } & Underweight & 46 & 41 & \multirow{2}{*}{.001} & Overweight & 41 & 88 & \multirow{2}{*}{.000} \\
\hline & & Not underweight & 228 & 19 & & Not overweight & 35 & 40 & \\
\hline & \multirow{2}{*}{ Girls } & Underweight & 38 & 68 & \multirow{2}{*}{.000} & Overweight & 86 & 88 & \multirow{2}{*}{.007} \\
\hline & & Not underweight & 246 & 11 & & Not overweight & 30 & 67 & \\
\hline
\end{tabular}

students who misperceived themselves as being underweight were more likely to inappropriately report attempting to gain weight, as compared to their normal-weight counterparts who accurately perceived their weight as being normal (using SPS: $47 \%$ versus $17 \%$ of the boys resp., $P<.01$; $27 \%$ versus $14 \%$ of the girls resp., $P<.01$ ). A similar association was found using the CEQ (41\% versus 19\% for boys, $P<.01 ; 68 \%$ versus $11 \%$ for girls, $P<.01$ ). With regard to weight loss among the overweight boys and girls, the overweight students appropriately attempted to lose weight more often if they accurately perceived themselves as overweight versus not (using SPS: $72 \%$ versus $44 \%$ of the boys, $P=.029 ; 86 \%$ versus $71 \%$ of the girls, $P=$ .068). A similar association was found with the CEQ $(88 \%$ versus $40 \%$ for boys, $P<.01 ; 88 \%$ versus $67 \%$ for girls, $P<.01)$. These results show an association between accurate perception of weight and appropriate weight-related behavior, although this association may not be clinically very important since weight loss behaviors were also found among a large proportion of overweight students who did not perceive themselves as such.

\section{Discussion}

We found a certain extent of inaccurate perception of one's own body weight among both the normal-weight and overweight students: a substantial proportion of the normalweight students perceived themselves as underweight, and a substantial proportion of the overweight students did not perceive themselves as overweight. We also found a certain extent of inappropriate weight-related behaviors: a substantial proportion of the normal-weight students were trying to gain weight, and a substantial proportion of the overweight students were not trying to lose weight. Finally, we found a relation between accurate weight perception and appropriate weight-related behavior, but this relationship was not strong emphasizing the role of other factors in determining weight-related behavior. We also found genderspecific patterns, where girls had leaner weight ideals than boys. These findings suggest behavioral factors that can fuel the obesity epidemic and/or limit the effectiveness of interventions to prevent obesity.
From a methodological perspective, both the closedended questionnaire (CEQ) and the Stunkard's pictorial silhouettes (SPS) gave relatively similar results in regard to perceived body image, as reported in other studies [13]. Based on the SPS, there was an overall good concordance between the actual weight status of the students and their perceived body image, consistent with previous reports [18]. Similarly, a large proportion of the students were able to accurately perceive their weight using the CEQ. In line with previous studies [9], girls seemed to have a more stringent perception of lean weight than boys as overweight girls were less likely than overweight boys to report being of normal weight. However, a substantial proportion of the overweight students did not perceive themselves as being overweight, consistent with previous studies $[9,36]$, and a substantial proportion of the normal-weight students perceived themselves as too lean. These findings point to motivational factors deterring appropriate weight-related behavior [9].

We found an association between accurate body image and appropriate weight-related behavior-using either CEQ or SPS instruments, although this association was not strong, as a number of overweight students reported attempting to lose weight without perceiving themselves as overweight. Interestingly, most of the overweight girls reported trying to lose weight when asked about their attempts to lose/gain weight, regardless of their perceived weight status, which may reflect new sociocultural trends favoring the thin-body image $[9,16]$. This suggests that while one's own accurate weight perception does play a role in appropriate weightcontrol behavior [8], other factors may also play a role, including gender, age, socioeconomic status [37], perceiving overweight as a health risk [38], and readiness for behavioral change [38, 39]. However, our findings still carry potential practical significance as correcting an individual's weight misperception might help improve appropriate weightcontrol behaviors.

The results indicated that normal-weight individuals who had a BID score of less than 0 (i.e., their current body image was smaller than their ideal body image) were more likely to attempt to gain weight, while overweight students who had a BID score of 0 or more were more likely to try to lose weight. 
With regard to one's desired body image, we found that girls had leaner own body size ideals compared to boys, regardless of their actual weight status, as reported in other studies $[9,14]$. Female adolescents may perceive thinness as being more attractive, and a low BMI has indeed been shown to be an important factor in determining female sexual attractiveness [40]. Male adolescents, on the other hand, had heavier body size ideals, which they may associate with physical strength and attractiveness [41]. This fairly lean body weight ideal seen among girls in our study (a majority being of African descent) has been found in only few other reports in black populations [42], with the majority of studies pointing to the preference of large body size ideals among black girls $[14,16,17]$. A trend towards a preference for a lean weight, which is getting increasingly promoted through the global mass media and/or heath awareness campaigns, may have a positive impact on future weight prevention and control strategies, with respect to the rising tide of obesity. However, most studies conducted in SubSaharan Africa have assessed perceptions of body image only among females (youth or adults) and not among males, possibly due to the usually higher prevalence of obesity among black women [43]. Our findings, together with the marked secular increase in the prevalence of overweight among both adult men and children over the past 15 years in the Seychelles [23,44] and in other countries, indicate the need to further assess males' perception of body image. Also of interest, we found that one's own body size ideals increased only little across thin, normal-weight, and overweight students (mean ideal silhouette score increased from 3.79 to 4.06): a slight increase is consistent with previous studies [31]. The finding that overweight students had, on average, a normal-weight body size ideal may have positive implications as thinner body ideals are associated with greater weight loss efforts [45].

Our study contributes to the existing literature on body image perception by providing data on body perception among adolescents of the Seychelles, as an example of a population of a rapidly developing country in the African region. Specifically, our study contributes information on the accuracy of body image perception according to actual weight status. Similar studies in other regions (United States, Canada, and the Middle East) $[8,9,30]$ have also found that many adolescents were unable to accurately perceive their actual weight status and that adolescents' weight perception was associated with weight-control behavior [8].

Our study also adds to the existing literature on body image perception in Africa. To our knowledge, no previous study among adolescents in the African region has examined the relationship between weight perception and weightrelated behavior. Our findings suggest that in the Seychelles, like in certain countries in other regions $[13,18]$, overweight might be valued as a symbol of health, beauty, or power. Clarifying adolescents' weight perceptions may therefore be a means to prevent tracking of inaccurate weight perception into adulthood, which may further fuel the obesity epidemic. A further strength of our study is that weight and height values were actually measured (and weight status objectively assessed), in contrast to a number of similar studies that have relied on self-reported values. However, it is possible that providing respondents with actual weight and height values (although not BMI) before administering the survey, as was done in this study, may have had an effect on body image perception, an issue which may affect the comparability of our results with previous findings in other studies. The fact that participants still report inaccurate perception of their weight status after having been given values of their own weight may strengthen the argument that perception of weight status has an effect independent of actual weight status. From a different perspective, this further stresses the case for addressing issues related to inaccurate weight perception, for example, through information on a healthy weight during science or health classes at school. Our study also has some limitations. As the prevalence of overweight and obesity is relatively low and our sample size is limited, we could not compare findings between overweight and obese students. In addition, it should be acknowledged that even if answers were obtained using selfadministered anonymous questions, social desirability may still play a role and some students may overreport weightcontrol behaviors. Furthermore, some misclassification can occur due to misunderstanding of the questions, which tends to favor null associations. Moreover, as information on pubertal status and parental socioeconomic status are not included as part of the GSHS questionnaire, we were unable to control for such covariates in our analyses.

\section{Conclusions}

Our findings indicate that substantial proportions of students have inaccurate perception of their weight and/or inappropriate weight-related behavior. These findings point to sociocultural forces that can drive secular obesity trends upwards. We also found that accurate perception of one's own weight was associated with appropriate weight-related behavior but this relationship was not strong. This suggests that addressing a child's perception of his/her own weight can be one avenue to help improve weight-control behavior, yet not a panacea. From a methodological perspective, adolescents' body image perception-as compared with actual weight status - was similar with either the SPS or CEQ instruments. More generally, our findings emphasize the importance of social and cultural factors related to accurate perception of one's own weight and appropriate weight-control behavior in youth and the need to consider such factors in programs and policies addressing weight, nutrition, and healthy lifestyles.

\section{Conflict of Interests}

The authors declare that they have no conflict of interests.

\section{Acknowledgments}

The authors thank the Ministry of Health and the Ministry of Education, Seychelles, the Centers for Disease Control and 
Prevention (Atlanta, USA), and the World Health Organization for their support. They also thank Pedro MarquesVidal and Gisela Marcelino for advice on early versions of this paper. The findings of this paper were presented in part at the 27th Annual Scientific Meeting of the Obesity Society, Washington, 24-28 October, 2009.

\section{References}

[1] WHO, Obesity: Preventing and Managing the Global Epidemic: Report of a WHO Consultation on Obesity, World Health Organization, Geneva, Switzerland, 1998.

[2] S. S. Guo, W. Wu, W. C. Chumlea, and A. F. Roche, "Predicting overweight and obesity in adulthood from body mass index values in childhood and adolescence," American Journal of Clinical Nutrition, vol. 76, no. 3, pp. 653-658, 2002.

[3] J. L. Baker, L. W. Olsen, and T. I. A. Sørensen, "Childhood body-mass index and the risk of coronary heart disease in adulthood," New England Journal of Medicine, vol. 357, no. 23, pp. 2329-2337, 2007.

[4] M. Neovius, J. Sundstrom, and F. Rasmussen, "Combined effects of overweight and smoking in late adolescence on subsequent mortality: nationwide cohort study," British Medical Journal, vol. 338, no. 7695, article b496, 2009.

[5] H. Fonseca and M. G. De Matos, "Perception of overweight and obesity among Portuguese adolescents: an overview of associated factors," European Journal of Public Health, vol. 15, no. 3, pp. 323-328, 2005.

[6] S. S. Gidding, A. H. Lichtenstein, M. S. Faith, A. Karpyn, J. A. Mennella, and B. Popkin, "Implementing American Heart Association pediatric and adult nutrition guidelines: a scientific statement from the American Heart Association nutrition committee of the council on nutrition, physical activity and metabolism, council on cardiovascular disease in the young, council on arteriosclerosis, thrombosis and vascular biology, council on cardiovascular nursing, council on epidemiology and prevention, and council for high blood pressure research," Circulation, vol. 119, pp. 1161-1175, 2009.

[7] E. Lynch, K. Liu, G. S. Wei, B. Spring, C. Kiefe, and P. Greenland, "The relation between body size perception and change in body mass index over 13 years: the Coronary Artery Risk Development in Young Adults (CARDIA) study," American Journal of Epidemiology, vol. 169, no. 7, pp. 857-866, 2009.

[8] Y. Wang, H. Liang, and X. Chen, "Measured body mass index, body weight perception, dissatisfaction and control practices in urban, low-income African American adolescents," BMC Public Health, vol. 9, article 183, 2009.

[9] A. M. Al-Sendi, P. Shetty, and A. O. Musaiger, "Body weight perception among Bahraini adolescents," Child, vol. 30, no. 4, pp. 369-376, 2004.

[10] N. K. Janz and M. H. Becker, "The Health Belief Model: a decade later," Health Education Quarterly, vol. 11, no. 1, pp. 1-47, 1984.

[11] J. O. Prochaska and C. C. DiClemente, "Stages and processes of self-change of smoking: toward an integrative model of change," Journal of Consulting and Clinical Psychology, vol. 51, no. 3, pp. 390-395, 1983.

[12] F. Kuchler and J. N. Variyam, "Mistakes were made: misperception as a barrier to reducing overweight," International Journal of Obesity, vol. 27, no. 7, pp. 856-861, 2003.

[13] Z. Mciza, J. H. Goedecke, N. P. Steyn et al., "Development and validation of instruments measuring body image and body weight dissatisfaction in South African mothers and their daughters," Public Health Nutrition, vol. 8, no. 5, pp. 509-519, 2005.

[14] C. Welch, S. M. Gross, Y. Bronner, N. Dewberry-Moore, and D. M. Paige, "Discrepancies in body image perception among fourth-grade public school children from urban, suburban, and rural Maryland," Journal of the American Dietetic Association, vol. 104, no. 7, pp. 1080-1085, 2004.

[15] E. Lynch, K. Liu, B. Spring, A. Hankinson, G. S. Wei, and P. Greenland, "Association of ethnicity and socioeconomic status with judgments of body size: the Coronary Artery Risk Development in Young Adults (CARDIA) Study," American Journal of Epidemiology, vol. 165, no. 9, pp. 1055-1062, 2007.

[16] A. A. Caradas, E. V. Lambert, and K. E. Charlton, "An ethnic comparison of eating attitudes and associated body image concerns in adolescent South African schoolgirls," Journal of Human Nutrition and Dietetics, vol. 14, no. 2, pp. 111-120, 2001.

[17] M. Holdsworth, A. Gartner, E. Landais, B. Maire, and F. Delpeuch, "Perceptions of healthy and desirable body size in urban Senegalese women," International Journal of Obesity, vol. 28, no. 12, pp. 1561-1568, 2004.

[18] R. T. Jackson, M. Rashed, and R. Saad-Eldin, "Rural urban differences in weigth, body image, and dieting behavior among adolescent Egyptian schoolgirls," International Journal of Food Sciences and Nutrition, vol. 54, no. 1, pp. 1-11, 2003.

[19] A. D. Powell and A. S. Kahn, "Racial differences in women's desires to be thin," International Journal of Eating Disorders, vol. 17, no. 2, pp. 191-195, 1995.

[20] K. J. Flynn and M. Fitzgibbon, "Body images and obesity risk among black females: a review of the literature," Annals of Behavioral Medicine, vol. 20, no. 1, pp. 13-24, 1998.

[21] S. Kumanyika, J. F. Wilson, and M. Guilford-Davenport, "Weight-related attitudes and behaviors of black women," Journal of the American Dietetic Association, vol. 93, no. 4, pp. 416-422, 1993.

[22] P. Rasheed, "Perception of body weight and self-reported eating and exercise behaviour among obese and non-obese women in Saudi Arabia," Public Health, vol. 112, no. 6, pp. 409-414, 1998.

[23] P. Bovet, A. Chiolero, G. Madeleine, A. Gabriel, and N. Stettler, "Marked increase in the prevalence of obesity in children of the Seychelles, a rapidly developing country, between 1998 and 2004," International Journal of Pediatric Obesity, vol. 1, no. 2, pp. 120-128, 2006.

[24] A. Chiolero, G. Paradis, G. Madeleine, J. A. Hanley, F. Paccaud, and P. Bovet, "Discordant secular trends in elevated blood pressure and obesity in children and adolescents in a rapidly developing country," Circulation, vol. 119, no. 4, pp. 558-565, 2009.

[25] A. M. Lasserre, B. Viswanathan, and P. Bovet, Seychelles 2007 Global School-Based Student Health Survey-Full Report, Ministry of Health and Social Development, Republic of Seychelles and University of Lausanne, 2008, http://www.who.int/ chp/gshs/Seychelles_GSHS_2008_long_report.pdf.

[26] B. Viswanathan, A. M. Lasserre, J. William, G. Madeleine, and P. Bovet, Seychelles 2007 Global School-Based Student Health Survey-Short Report, Ministry of Health and Social Development, Republic of Seychelles and University of Lausanne, Switzerland, 2008, http://www.who.int/chp/gshs/Seychelles_GSHS_2008_short_report.pdf.

[27] C. M. Bulik, T. D. Wade, A. C. Heath, N. G. Martin, A. J. Stunkard, and L. J. Eaves, "Relating body mass index to figural stimuli: population-based normative data for Caucasians," 
International Journal of Obesity, vol. 25, no. 10, pp. 1517-1524, 2001.

[28] E. Gualdi-Russo, A. Albertini, L. Argnani, F. Celenza, M. Nicolucci, and S. Toselli, "Weight status and body image perception in Italian children," Journal of Human Nutrition and Dietetics, vol. 21, no. 1, pp. 39-45, 2008.

[29] M. Kaufer-Horwitz, J. Martínez, L. M. Goti-Rodríguez, and H. Ávila-Rosas, "Association between measured BMI and self-perceived body size in Mexican adults," Annals of Human Biology, vol. 33, no. 5-6, pp. 536-545, 2006.

[30] K. Maximova, J. J. McGrath, T. Barnett, J. O’Loughlin, G. Paradis, and M. Lambert, "Do you see what I see? Weight status misperception and exposure to obesity among children and adolescents," International Journal of Obesity, vol. 32, no. 6, pp. 1008-1015, 2008.

[31] S. Potti, M. Milli, S. Jeronis, J. P. Gaughan, and M. Rose, "Self-perceptions of body size in women at an inner-city family-planning clinic," American Journal of Obstetrics and Gynecology, vol. 200, no. 5, pp. e65-e68, 2009.

[32] R. S. Strauss, "Self-reported weight status and dieting in a cross-sectional sample of young adolescents: National Health and Nutrition Examination Survey III," Archives of Pediatrics and Adolescent Medicine, vol. 153, no. 7, pp. 741-747, 1999.

[33] A. J. Stunkard, T. Sørensen, and F. Schulsinger, "Use of the Danish Adoption Register for the study of obesity and thinness," Research Publications-Association for Research in Nervous and Mental Disease, vol. 60, pp. 115-120, 1983.

[34] T. J. Cole, M. C. Bellizzi, K. M. Flegal, and W. H. Dietz, "Establishing a standard definition for child overweight and obesity worldwide: international survey," British Medical Journal, vol. 320, no. 7244, pp. 1240-1243, 2000.

[35] T. J. Cole, K. M. Flegal, D. Nicholls, and A. A. Jackson, "Body mass index cut offs to define thinness in children and adolescents: international survey," British Medical Journal, vol. 335, no. 7612, pp. 194-197, 2007.

[36] S. Paeratakul, M. A. White, D. A. Williamson, D. H. Ryan, and G. A. Bray, "Sex, race/ethnicity, socioeconomic status, and BMI in relation to self-perception of overweight," Obesity Research, vol. 10, no. 5, pp. 345-350, 2002.

[37] H. Al Sabbah, C. Vereecken, Z. Abdeen et al., "Weight control behaviors among overweight, normal weight and underweight adolescents in Palestine: findings from the national study of Palestinian schoolchildren (HBSC-WBG2004)," International Journal of Eating Disorders, vol. 43, no. 4, pp. 326-336, 2010.

[38] C. C. Wee, R. B. Davis, and R. S. Phillips, "Stage of readiness to control weight and adopt weight control behaviors in primary care," Journal of General Internal Medicine, vol. 20, no. 5, pp. 410-415, 2005.

[39] E. M. F. Van Sluijs, M. N. M. Van Poppel, and W. Van Mechelen, "Stage-based lifestyle interventions in primary care: are they effective?" American Journal of Preventive Medicine, vol. 26, no. 4, pp. 330-343, 2004.

[40] M. J. Tovee, S. Reinhardt, J. L. Emery, and P. L. Cornelissen, "Optimum body-mass index and maximum sexual attractiveness," Lancet, vol. 352, no. 9127, p. 548, 1998.

[41] D. S. Maisey, E. L. E. Vale, P. L. Cornelissen, and M. J. Tovee, "Characteristics of male attractiveness for women," Lancet, vol. 353, no. 9163, p. 1500, 1999.

[42] R. B. Duda, N. A. Jumah, A. G. Hill, J. Seffah, and R. Biritwum, "Assessment of the ideal body image of women in Accra, Ghana," Tropical Doctor, vol. 37, no. 4, pp. 241-244, 2007.

[43] Y. Wang and M. A. Beydoun, "The obesity epidemic in the United States-gender, age, socioeconomic, racial/ethnic, and geographic characteristics: a systematic review and meta-regression analysis," Epidemiologic Reviews, vol. 29, no. 1, pp. 6-28, 2007.

[44] P. Bovet, A. Chiolero, C. Shamlaye, and F. Paccaud, "Prevalence of overweight in the Seychelles: 15 year trends and association with socio-economic status," Obesity Reviews, vol. 9, no. 6, pp. 511-517, 2008.

[45] B. I. Canpolat, S. Orsel, A. Akdemir, and M. H. Ozbay, "The relationship between dieting and body image, body ideal, self-perception, and body mass index in Turkish adolescents," International Journal of Eating Disorders, vol. 37, no. 2, pp. 150-155, 2005. 


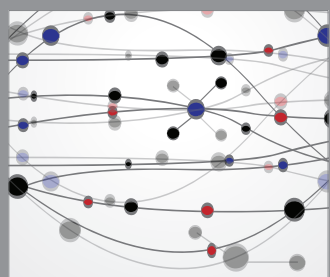

The Scientific World Journal
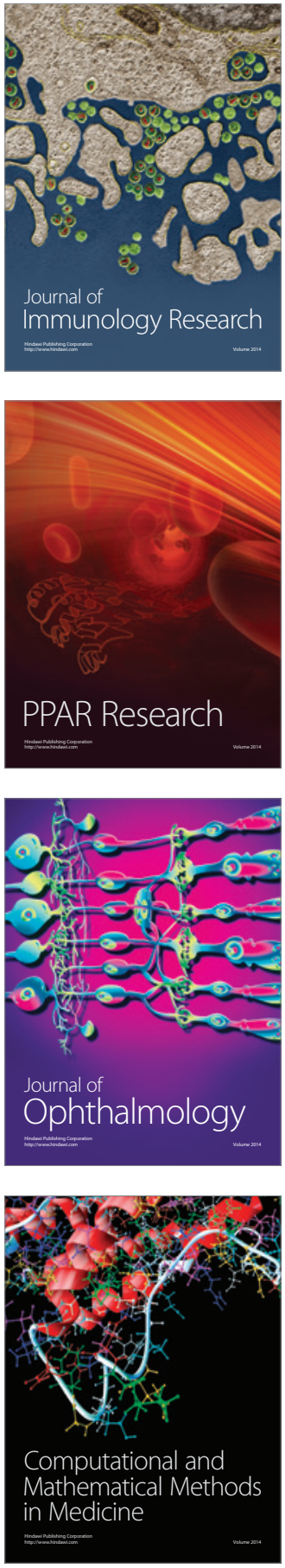

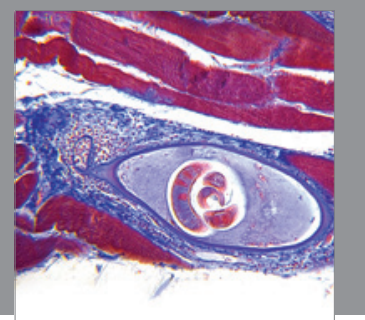

Gastroenterology

Research and Practice
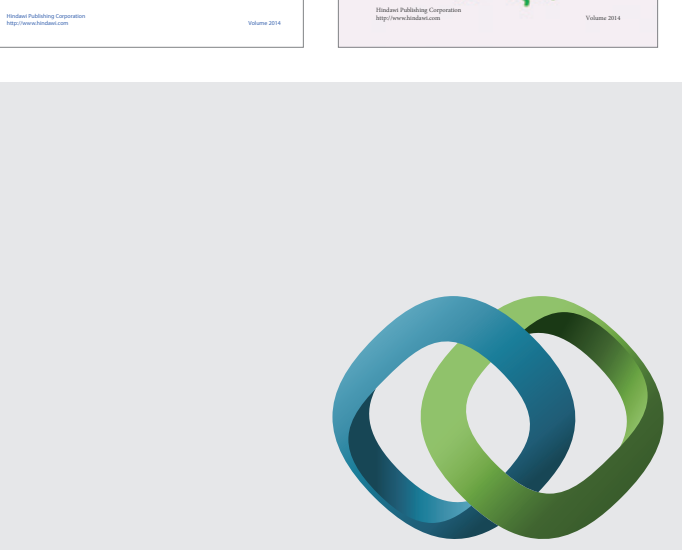

\section{Hindawi}

Submit your manuscripts at

http://www.hindawi.com
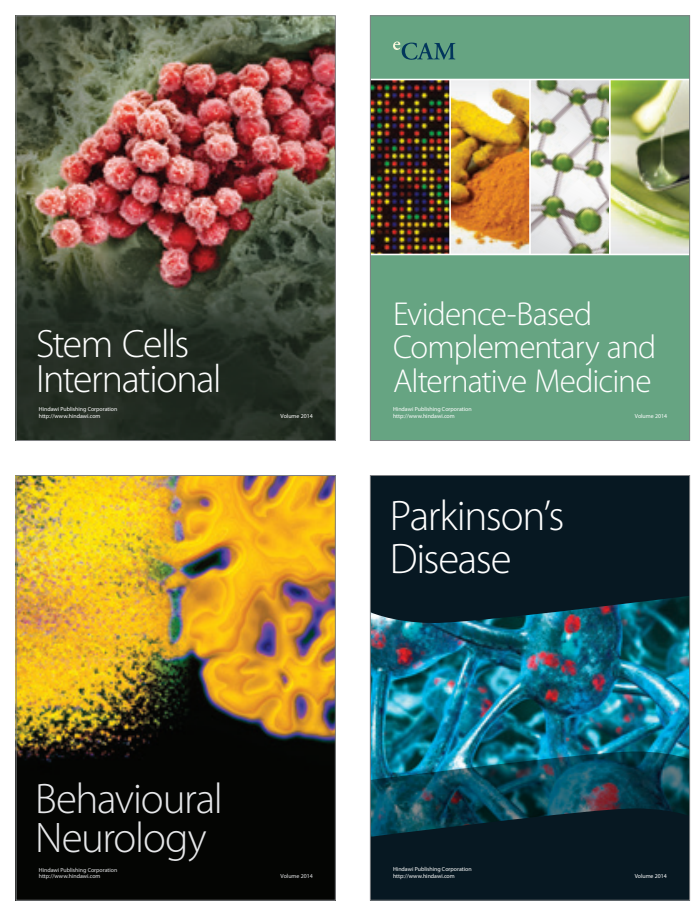

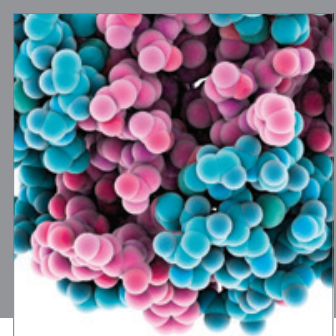

Journal of
Diabetes Research

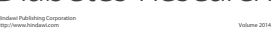

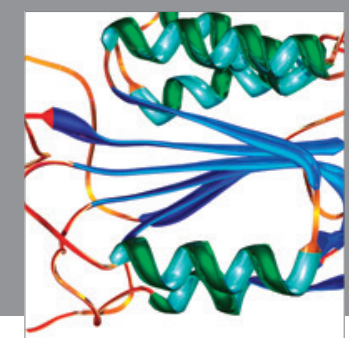

Disease Markers
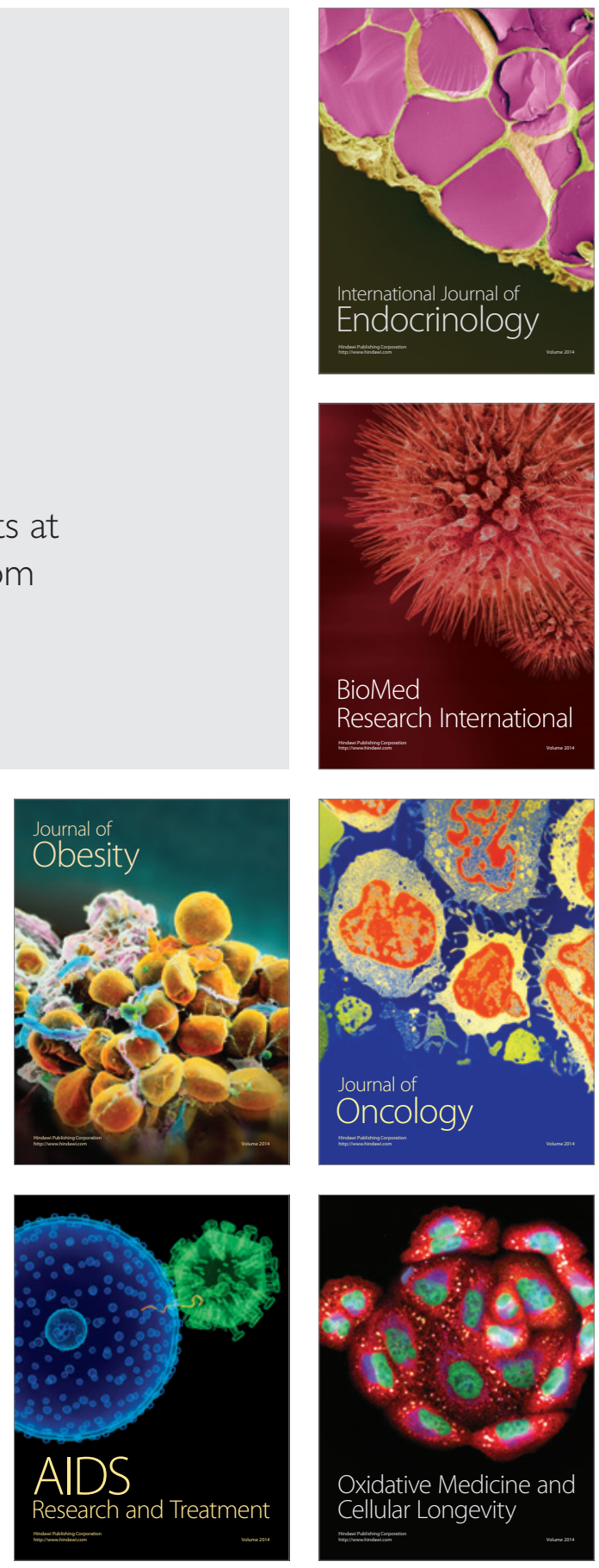